\title{
EEG changes after 1,4, and 7 days of sensory deprivation: A cross-sectional approach $^{1}$
}

JOHN P. ZUBEK. JEAN MARY SHEPHARD, and S. L. MILSTEIN, University of Manitoba, Winnipeg, Canada

Three groups of Ss, exposed to 1,4, or 7 days of sensory deprivation (darkness and silence), all showed a significant post-isolation decrease in occipital alpha frequencl: Howeler, no indication of a progressive decrease in mean alpha frumuency as a function of increasing duration of sensory deprivation was obtained. a finding contrary to that reported in several earlier studies employing a longitudinal approach. After each of the three durations, the magnitude of the post-isolation decrease was approximately $1 \mathrm{~Hz}$. It was concluded that a different temporal pattern of EEG changes may occur. depending on whether a cross-sectional or longitudinal test procedure is employed, a finding of considerable importance for future research in the area of sensory and perceptual deprivation.

Changes in electrical activity of the brain during sensory isolation were first reported in a study conducted at McGill University (Heron, 1957). Daily EEG records obtained from six Ss who completed 4 days of perceptual deprivation revealed slow alpha waves of high voltage and marked delta-wave activity. Further analysis, using a period-count technique (Engel et al, 1944) to measure occipital alpha frequency, showed a progressive slowing of EEG activity with increasing duration of isolation, i.e., more slow activity was evident after 4 days than after 2 , in all six Ss. This regular progression was still present even when the tracings were analyzed in 24-h time blocks. Using the same period-count technique, a similar decrease in alpha frequency with time was also reported by Gendreau et al (1968) in Ss tested at invervals of $0,1,4$, and 7 days of a 1-week deprivation period and by Zubek (1964) in Ss tested at intervals of 0 , 7,10 , and 14 days of a 2 -week period. In all of these studies, it is important to note, a longitudinal testing procedure was employed: the EEG records were taken from the same Ss at periodic intervals during a prescribed period of isolation. The purpose of this experiment was to determine if a similar progressive decrease in alpha frequency would occur with a cross-sectional test procedure, i.e., using three different groups of Ss each exposed to 1,4 , or 7 days of deprivation, durations corresponding to the test periods employed in the Gendreau et al (1968) and Heron (1957) longitudinal studies. Certain preliminary results obtained in this laboratory suggested that these two experimental approaches might not produce the same temporal pattern of EEG changes.

\section{METHOD}

Twenty male undergraduate students, subdivided into two groups of $10 \mathrm{Ss}$ each, were placed individually in an air-conditioned isolation chamber (for details. see Zubek. Sansom. \& Prysiazniuk. 1960) for a prescribed period of either 1 day or 4 days. All Ss were informed, beforehand. of the expected duration of the isolation. They were required to lie quietly on a mattress under a condition of constant darkness and silence. They could sit up or stand up only while eating or while using the toilet facilities located in the floor of the chamber. Singing, humming, or any other vocal activity was not permitted. EEG tracings were taken on an Offner eight-channel, Type $T$ machine before and after the completion of either 1 or 4 days of isolation, the records being taken at the same time of the day (10 a.m.) on each pre- and posttest session. Sixteen Ediswan monopad electrodes were applied to the head in International Federation 10/20 positions and two S.L.E. suction electrodes were applied to the ears. Average, bipolar, and monopolar recordings were taken.

In order to obtain a quantitative measure of EEG changes, the period count technique (Engel et al, 1944) was used to determine the occipital alpha frequency of each S. Mean values were calculated from 2001 -sec samples of artifact-free occipital lobe tracings, where sufficient countable wave activity of alpha frequency was available. In several cases, a somewhat

\section{Table 1}

Mean Occipital Alpha Frequency Before and After Either 1, 4, or 7 Days of Sensory Deprivation or of a Control Condition (10 Ss in Each of 6 Groups)

\begin{tabular}{|c|c|c|c|c|c|c|c|c|c|}
\hline \multirow[b]{2}{*}{ Groups } & \multicolumn{3}{|c|}{1 Day } & \multicolumn{3}{|c|}{4 Days } & \multicolumn{3}{|c|}{7 Days } \\
\hline & Pre & Post & Difference & Pre & Post & Difference & Pre & Post & Difference \\
\hline $\begin{array}{l}\text { Sensory } \\
\text { Deprivation }\end{array}$ & 10.58 & 9.66 & -0.92 & 10.79 & 9.71 & -1.08 & 10.78 & 9.93 & -0.85 \\
\hline $\begin{array}{l}\text { Control } \\
\text { Condition }\end{array}$ & 10.24 & 10.24 & 0.00 & 10.33 & 10.34 & +0.01 & 10.49 & 10.50 & +0.01 \\
\hline
\end{tabular}

smaller sample had to be employed. A similar EEG recording and analysis procedure was also applied to 20 ambulatory control Ss, 10 tested before and after 1 day and 10 before and after 4 days. These Ss were not isolated; they merely came to the laboratory on two separate occasions, either 1 or 4 days apart. The results on these two experimental and two control groups were then compared with the results of 20 male undergraduate students employed in an earlier study (Zubek \& Welch, 1963). Half of these were experimental Ss from whom EEG records were taken before and after 7 days of darkness and silence, and the other half were ambulatory controls, tested twice, a week apart. All Ss were again informed, beforehand, of the expected duration of the experiment, i.e., 7 days.

\section{RESULTS}

Table 1 shows the mean occipital alpha frequency obtained before and after 1, 4, or 7 days of sensory deprivation or of a control condition. It can be seen that the three control groups show virtually a zero change in frequency. On the other hand, the three experimental groups show a mean post-isolation decrease of approximately $1 \mathrm{~Hz}$ after each deprivation period. All decreases were statistically significant (ps $<.02$ ). Finally, an analysis of variance comparing the magnitude of the post-isolation decreases occurring after 1 , 4 , and 7 days yielded a nonsignificant F ratio.

\section{DISCUSSION}

In contrast to the results of previous research (Gendreau et al, 1968; Heron, 1957; Zubek, 1964) in which the same Ss were tested periodically during a prescribed duration of isolation, the present results, derived from a cross-sectional approach, revealed no indication of a progressive decrease in alpha frequency over days. The magnitude of the postisolation decrease was the same, approximately $1 \mathrm{~Hz}$, regardless of whether a 1-, 4-, or 7-day duration was employed. These results are puzzling, particularly in view of the progressive decrease in alpha frequency reported by Gendreau et al (1968), who tested at the same durations $(1,4$, and 7 days) and employed the same EEG period-count technique as in the present 
study. The only difference was the use of a. longitudinal test procedure.

Of the various theories that have been postulated to account for the various deprivation effects reported in the literature (see Schultz, 1965; Zubek, 1969), the set-expectancy hypothesis of Jackson \& Pollard (1962) appears to be the most pertinent in interpreting the present findings. According to this hypothesis, the experimental Ss may have developed a set, or "preparedness," to complete a goal-oriented task (successful endurance of isolation), this set being unrelated to the duration required for its completion. If this were the case, the magnitude of the decrease in alpha frequency for each of the different duration-groups might be approximately the same. Although this does not explain how or why set should operate in this manner, it is interesting to note that two recent studies have indicated that "preparedness," or set, for a given duration can be an important factor in determining the magnitude of EEG changes observed in isolation experiments. In the first, Saunders \& Zubek (1967) employed two groups of perceptually deprived Ss: a group isolated for a prescribed period of 1 week and a group isolated for 2 weeks. All Ss in each group were informed beforehand of the duration of the experiment. The results revealed that the 7 -day group exhibited a decrease of $11 \%$ in mean alpha frequency at the end of 7 days, while the 14-day group showed a decrease of only $5 \%$ over the same duration (first 7 days). In the second study, conducted by the Russian investigators Lebedinsky, Levinsky, \& Nefedov (1964), a similar phenomenon was reported. The "EEG changes at the end of a 10-day social isolation experiment were considerably more pronounced than those occurring at the end of the first 10 days of a two-month experiment." In both of these studies, therefore, the difference in the magnitude of the EEG change apparently is related to what the Ss were told beforehand as to the expected duration of the experiment.

Further evidence suggesting that EEG activity may be influenced by set or "preparedness" was reported by Kamiya (1967), who observed that Ss could not only signal to an $\mathrm{E}$ when changes were taking place in their alpha records, but could also learn to modify the records by controlling their "state of mind." Although these findings, which were demonstrated in a nonisolated situation, may not be directly applicable in the present case, they are, nevertheless, important in suggesting that the nature of EEG records obtained in sensory isolation studies probably can be affected by the specific types of instructions provided the $S$ s prior to the experiment, or by any sets and expectancies that they may have developed on theis own during the period of isolation.

Although a set-expectancy hypothesis is tentatively offered as a possible explanation of our findings, further research is required to clarify their nature and the mechanisms involved. Three types of future studies may prove fruitful. First what is the nature of the relationship between the magnitude of the alpha frequency decrease and various other durations of deprivation not employed in the present study? This line of investigation is important, particularly since Marjerrison \& Keogh (1967), using the Engel period count technique, have reported a decrease of $0.25 \mathrm{~Hz}$ at the end of a 1-h perceptual deprivation experiment, a decrease whose magnitude is considerably below that observed in the present study. Second, what is the rate of EEG "recovery" in Ss who have been deprived for periods of 1, 4, or 7 days? Although the magnitude of the decrease in alpha frequency may be the same for the three different durations, it is possible that the 7-day Ss may require a longer postisolation recovery period to retum to their normal, preexperimental alpha frequency than do those exposed to the shorter durations. Third, since set appears to be implicated in this EEG phenomenon, a systematic exploration of its possible role should be attempted. For example, the Ss may be told to enter isolation "for as long as you can take it," or the initially prescribed duration may be lengthened or shortened by the $E$ while $S$ is already in isolation. Further research directed at these and other related problems may clarify the nature of the present findings. In conclusion, the results of this study are of considerable importance for future research in the area of sensory and perceptual deprivation. They suggest that a different temporal pattern of performance, not only on physiological, but also on behavioral measures may occur depending on whether a longitudinal or cross-sectional test procedure is employed.

\section{REFERENCES}

ENGEL, G. L., ROMANO, J., IERRIS, E. B. WEBB, J. P., \& STEVENS, C. D. A simple method of determining frequency spectrums in the electroencephalogram. Archives of Neurology \& Psychiatry, 1944, 51, 134-146. GENDREAU, P., FREEDMAN, N. L., WILDE, G. J. S., \& SCOTT, G. D. The effect of 7 days of perceptual deprivation on the visual evoked potential and EEG frequency. Canadian Psychologist, 1968, 9. 278 (Abstract).

HERON, W. Cognitive and physiological effects of perceptual isolation. In $\mathrm{P}$. Solomon et al (Eds.), Sensory deprivation. Cambridge: Harvard University Press. 1961. Pp. 6-33.

JACKSON, C. W., \& POLlaRD. J. C. Sensory deprivation and suggestion: $A$ theoretical approach. Behavioral Science, 1962,7, 332-343.

KAMIYA, J. EEG operant conditioning and the study of the states of consciousness. Paper presented at the annual meeting of the American Psychological Association. Washington, D.C., September 1967.

LEBEDINSKY, A. V., LEVINSKY, S. V., \& NEFEDOV, Y. G. General principles concerning the reaction of the organism to the complex environmental factors existing in spacecraft cabins. Paper presented at the XV International Aeronautical Congress, Warsaw, September 1964. Translated from Russian by NASA, TTF -273 .

MARJERRISON, G., \& KEOGH, R. P. Electroencephalographic changes during brief periods of perceptual deprivation. Perceptual \& Motor Skills, 1967, 24, 611-615.

SAUNDERS, M. G.. \& ZUBEK. J. P. EEG changes in perceptual and sensory deprivation. Electroencephalography \& Clinical Neurophysiology, 1967. Suppl. 25, 246-257.

SCHULTZ, D. P. Sensory restriction. New York: Academic Press. 1965.

ZUBEK, J. P. Behavioral and FEG changes after 14 days of perceptual deprivation. Psychonomic Science, 1964, 1.57-58.

ZUBEK, J. P. (Ed.), Sensory deprivation: Fifteen years of research. New York: Appleton-Century-Crofts, 1969.

Z UBEK, J. P. \& WELCH, G Electroencephalographic changes after prolonged sensory and perceptual deprivation. Science, 1963.139, 1209-1210.

ZUBEK, J. P., SANSOM, W., \& PRYSIAZNIUK, A. Intellectual changes during prolonged isolation (darkness and silence). Canadian Journal of Psychology, 1960, 14. 233-243. NOTE

1. This research was supported by the Defence Research Board, Canada (No. 9425-08) and by the National Research Council, Canada (APA-290). 